\title{
Duodenal involvement in Gardner's syndrome
}

\author{
R. N. MELMED ${ }^{1}$ AND I. A. D. BOUCHIER \\ From the Department of Medicine, The Royal Free Hospital, London
}

SUMMARY It is suggested that duodenal polyps are more frequent in Gardner's syndrome than previously recognized. The polyps have a particular tendency to undergo malignant change. Two patients with Gardner's syndrome are reported in whom duodenal polyps were associated in one patient with periampullary cancer and in the other with a possible adenocarcinoma of the duodenum.

The association in a patient of multiple polyposis coli, osteomata, and soft tissue tumours was first reported by Devic and Bussey (1912), but it was not until Gardner and Richards (1953) drew attention to the genetically determined association of this group of lesions that such patients have been identified as having a disorder different from multiple polyposis coli with osteomata and soft tissue tumours. There have been a number of reports documenting an increasing variety of soft tissue tumours in association with this syndrome and the subject has been reviewed by several authors (Gorlin and Chaudhry, 1960; Jones and Cornell, 1966; Weston and Wiener, 1967).

There have been previous reports of involvement of the pancreas and duodenum in Gardner's syndrome. One of the earliest is of a 36-year-old man who died with a 'periampullary' carcinoma. $\mathrm{He}$ was found in addition to have polyps of the entire gastrointestinal tract, including the duodenum (Cabot, 1936). Gorlin and Chaudhry (1960) report on a patient with Gardner's syndrome in whom a single polyp of the third part of the duodenum was discovered accidentally on a barium meal. Macdonald, Davis, Crago, and Berk (1967) describe two patients with this syndrome, one who had an adenocarcinoma of the pancreas and the other with an adenocarcinoma of the ampulla of Vater. Duncan, Dohner, and Priest (1968) report a patient with Gardner's syndrome who had part of the duodenum and proximal jejunum resected for polyps which were associated with intestinal bleeding, epigastric discomfort, and postprandial nausea. He refused colonic resection. Four years later he died

Reprint requests to: Dr Ian A. D. Bouchier, M.D., F.R.C.P., Reader in Medicine, The Royal Free Hospital, Gray's Inn Road, WC1X 8LF

Received for publication 27 April 1972. and at necropsy widespread secondary carcinomatosis and intestinal obstruction due to an adenocarcinoma of the duodenum were discovered. There was no evidence of malignancy in numerous polyps of the colon. This patient's son developed polyps at 16 years of age. These were removed together with the colon and all polyps (in duodenum and colon) were shown to be histologically benign.

The present report describes two patients with Gardner's syndrome both of whom had multiple polyps of the duodenum and in one of whom there was a superimposed adenocarcinoma. A review of the literature suggests that patients with Gardner's syndrome have a particular propensity for duodenal polyposis and malignancy.

\section{Case Reports}

1 Patient B.s.

This patient is a woman aged 39 years who first presented at the age of 22 years with diarrhoea and blood and mucus in the stools. A barium enema suggested a diagnosis of ulcerative colitis. A repeat barium enema four years later (1956) showed multiple polyposis and a total colectomy was performed with subtotal excision of the rectum and an ileo-rectal anastomosis. Histological examination of the resected colon showed malignant change in four areas. In April 1959 malignant polyps were diagnosed by rectal biopsy and the patient underwent an abdominoperineal excision of the rectum. She was readmitted for further investigation in 1966 because of a twoyear complaint of increasing lethargy.

There was no family history of multiple polyposis coli. The patient's father had an operation for carcinoma of the larynx but died some years later at 74 years of a cerebrovascular accident. The mother is alive and well at 73 years. Both her brother and 16- 
year-old daughter were found to be free of colonic polyps on barium enema examination.

Physical examination showed a well nourished patient with a normally functioning ileostomy. There was a scar on the dorsum of the right hand following removal of a 'sebaceous cyst' excised 19 years previously. A capillary haemangioma was present on the right forearm and a cystic subcutaneous swelling about $2 \mathrm{~cm}$ in diameter over the inferior surface of the right tibia. This was believed to be a sebaceous cyst. There was no buccal or skin pigmentation and clinical examination of the thyroid, breasts, cardiovascular, respiratory, and nervous systems was normal. Blood pressure was 120/80 $\mathrm{mm} \mathrm{Hg}$. Examination of the abdomen revealed an ill defined, fixed, firm, painless mass in the right iliac fossa.

All routine investigations, including a full blood count, liver function tests, and tests of small bowel function, were within normal limits.

A small bowel enema was normal but gas distension double-contrast hypotonic duodenography showed multiple polyps of the duodenum with a constant filling defect at the junction of the second and third parts of the duodenum (Fig. 1). Radiographs of the jaws showed areas of osteosclerosis possibly indicative of ossifying fibromata. Gastroscopy showed a normal mucosa.

A biopsy from the third part of the duodenum was performed with a Crosby capsule. Histological section showed that in addition to the normal duodenal mucosa, there was a number of adenomatoid fragments composed of gland tubules crowded together and lined by large hyperchromatic epithelial cells (Fig. 2). Although the appearances could have represented an adenomatous polyp, a well differentiated columnar cell adenocarcinoma could not be excluded.

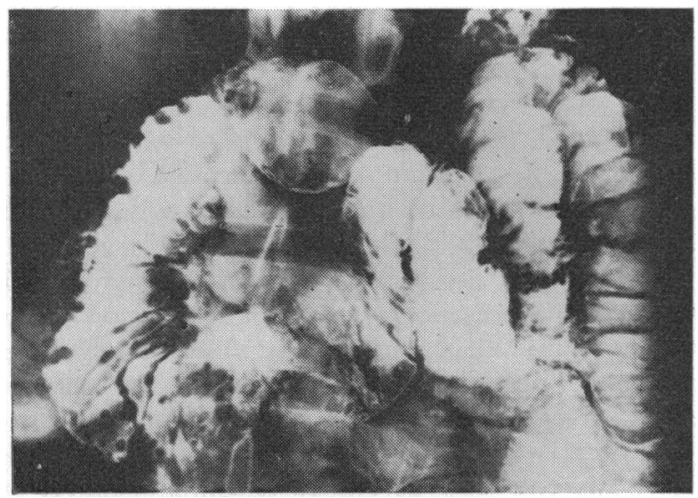

Fig. 1 Hypotonic duodenography in B.S. showing multiple duodenal polyps.

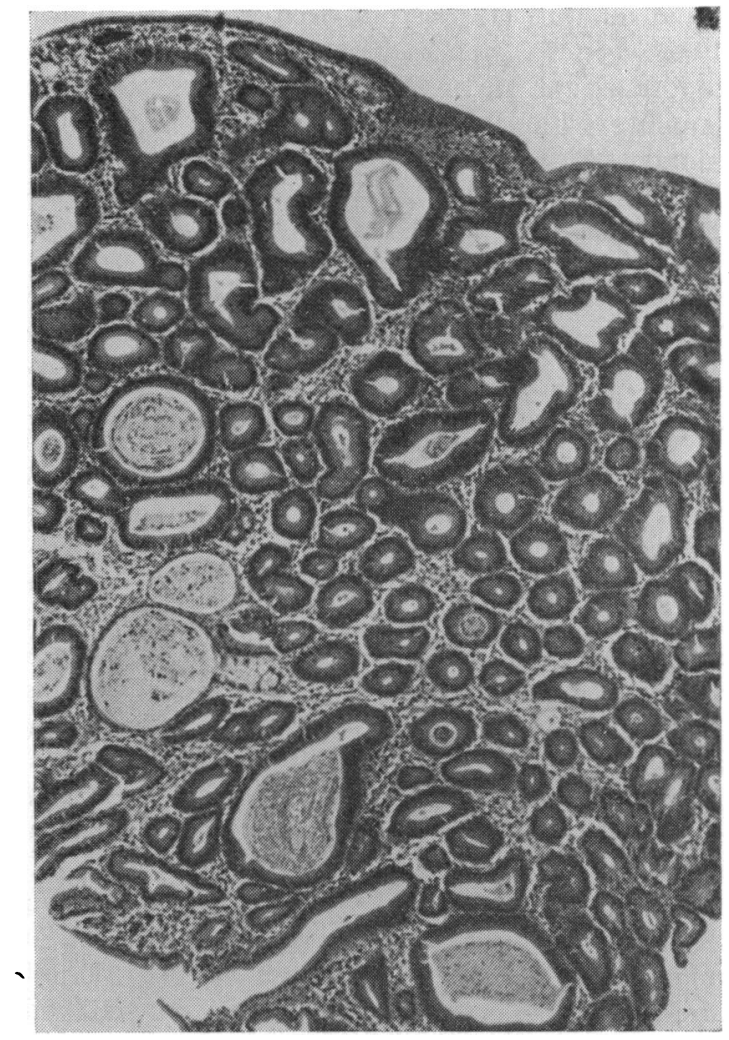

Fig. 2 Peroral biopsy from third part of duodenum

in B.S. showing an adenomatoid fragment with crowded glands lined by large hyperchromatic epithelial cells $(\times 35)$.

A laparotomy was performed and the duodenal filling defect was shown to be an extrinsic impression from a large fibromatous retroperitoneal mass. The duodenum felt normal and it was not possible to palpate the polyps seen on duodenography and reported on histologically. A duodenostomy was not performed.

\section{PATIENT H.P.}

This patient, a 60-year-old man, gave a history of passing bright red blood per rectum intermittently since the age of 20 years. In 1952, at the age of 44 years, cancer of the rectum was diagnosed and an abdomino-perineal resection with colostomy was performed. Numerous polyps were noted in the colon. He refused to have the colon removed and barium enema examinations were performed at sixmonth intervals. In 1955, a cancer of the ascending colon was diagnosed and a colectomy with ileostomy was performed.

In 1965 he underwent removal of a right parotid 
gland tumour. He was first seen at this hospital in 1968 when six months before admission he began to lose weight. He noted the gradual development of jaundice with slight pruritus and on occasions a number of rigors associated with fever.

His father died aged 94 from arteriosclerosis. His mother died at the age of 54 from an operation for colonic obstruction and there is the probability that she had cancer of the colon. Three brothers are alive and well. His wife is well. His two children, a boy aged 19 and girl aged 17, are both well and followed up at a clinic.

Physical examination showed a jaundiced man with evidence of recent weight loss. There were no signs of chronic liver disease. A bony hard mass, $1.5 \times 1.5 \mathrm{~cm}$, was present on the left parietal area and another similar-sized mass on the centre of the hard palate. There was a scar over the right parotid area. There were no abnormal signs in the cardiovascular, respiratory, and central nervous systems. Blood pressure was $120 / 65$. Examination of the abdomen showed an ileostomy in the right iliac fossa and the scars of previous surgery. The liver was $4 \mathrm{~cm}$ enlarged below the costal margin and was smooth, firm, and painless.

Routine haematological tests were normal but his serum biochemistry showed a bilirubin of 7.0 $\mathrm{mg} / 100 \mathrm{ml}$ (conjugated bilirubin $6.2 \mathrm{mg} / 100 \mathrm{ml}$ ) and an alkaline phosphatase of $70 \mathrm{KA}$ units $/ 100 \mathrm{ml}$.

A liver biopsy showed features strongly suggestive of large duct obstruction with bile-duct proliferation and dilatation, bile extravasates, portal tract oedema, and signs of acute inflammation. Hypotonic duodenography revealed multiple polypoidal filling defects particularly well seen in the third part. In the second part of the duodenum there was marked distortion and loss of the normal mucosal pattern. The appearance suggested multiple duodenal polyps with a superimposed cancer. A percutaneous cholangiogram showed dilatation with obstruction at the lower end of the common bile duct. At laparotomy a hard mass found in the region of the second and third parts of the duodenum was resected. Histology showed the duodenal mucosa to be invaded by an adenocarcinoma of varying differentiation. In places the lesion was papillary in structure. Examination of mucosa away from the main mass showed a papillary growth with carcinomatous change. The impression was one of a carcinoma of multicentric origin arising from a papillary surface.

\section{Discussion}

The association in both these patients of multiple polyposis coli, osteomata, and soft tissue tumours justifies the diagnosis of Gardner's syndrome. It is probably fortuitous that neither patient has a positive family history but because we have been unable to investigate the relatives, this possibility cannot be excluded. It may be significant that one parent of B.S. had cancer of the colon and a parent of H.P. had cancer of the larynx. Absence of a supporting family history, though uncommon, has previously been reported in Gardner's syndrome (Gorlin and Chaudhry, 1960; Bochetto, Raycroft, and De Innocentes, 1963). As in multiple polyposis coli (Veale, 1960), the offspring of random cases of Gardner's syndrome are liable to inherit the disease, transmitted as a Mendelian, non-sex-linked dominant gene (Bochetto et al, 1963.)

The development of obstructive jaundice in H.P. immediately focused attention on the pancreatoduodenal area. The histological appearances were suggestive of duodenal carcinoma of multicentric origin and secondary involvement of the ampullar region although a primary neoplasm of the ampulla of Vater could not be excluded with certainty. It was much more difficult to make the diagnosis of multiple duodenal polyps in B.S. because there were no symptoms referable to the upper gastrointestinal tract. The polyps were demonstrated on hypotonic duodenography (Fig. 1) and the diagnosis was confirmed by peroral biopsy (Fig. 2). It should be noted that the polyps did not show on the routine barium meal undertaken before duodenography; nor were they felt on careful palpation of the duodenum at laparotomy at a time when their presence was known.

From our review of the literature and these two patients it is apparent that duodenal involvement in Gardner's syndrome may be more widespread than has been realized and it is apparent that the demonstration of small soft mucosal polyps may elude both routine radiological and surgical detection. Furthermore, of these six patients with Gardner's syndrome and multiple polyps in the duodenum, four had associated adenocarcinoma in and around the ampulla of Vater. One had a very suspicious histological picture in which malignancy could not be excluded. The sixth patient, who was 16 years old when first diagnosed, underwent immediate operative removal of the duodenal polyps which were histologically benign (Duncan et al, 1968).

Adhering to the criteria listed previously which included the presence of osteomata and soft tissue tumours, not all patients with multiple polyposis coli and multiple primary malignancies can be classified as Gardner's syndrome. However, there have been two case reports of patients with multiple polyposis coli who developed a primary cancer of both the colon and duodenum. One patient had periampullary carcinoma of the duodenum in the 
presence of duodenal polyps, carcinoma of the larynx, and molluscum sebaceum (Muir, Yates, Bell, and Barlow, 1967). The second patient had primary carcinoma of the ampulla of Vater and of the bladder (Capps, Lewis, and Gazzaniga, 1968). Although neither of these patients had osteomata or soft tissue tumours which are normally associated with Gardner's syndrome it is possible that they represent a variant of this syndrome.

Primary cancer of the duodenum is rare. Howard (1943) found 58 cases of duodenal carcinoma in 117433 necropsies (an incidence of $0.047 \%$ ). Of these, $26(45 \%)$ occurred in the second part of the duodenum; Iovine and Tsangaris (1961) found 48\% of 602 reviewed cases to have originated in the periampullary region. With less than 150 cases of Gardner's syndrome reported in the lierature, duodenal carcinoma would appear to occur with a much greater frequency in this condition. The tendency for carcinoma to develop in the ampulla of Vater or periampullary mucosa in Gardner's syndrome may reflect the predilection of the second and third parts of the duodenum to develop carcinoma.

Although the precise incidence of duodenal involvement in Gardner's syndrome has not been determined the available experience suggests that special attention should be given to this area. Early detection of duodenal polps must alert the clinician to the hazard of the presence or subsequent development of duodenal carcinoma.

We are grateful to Dr L. Kreel for the radiological examination, to Dr I. P. Beswick for the histological reports, and to $\mathrm{Mr} \mathrm{C}$. Lyn who took the photo- graphs. We wish to thank Mr S. O. Aylett and Professor S. Sherlock who permitted us to study these patients.

\section{References}

Bochetto, J. F., Raycroft, J. F., and De Innocentes, L. W. (1963). Multiple polyposis, exostosis and soft tissue tumours. Surg. Gynec. Obstet., 117, 489-494.

Cabot, R. C. (Ed.) (1935). Case records of the Massachusetts General Hospital; Case 21061. New Engl. J. Med., 212, 263-267.

Capps, W. F., Jr., Lewis, M. I., and Gazzaniga, D. A. (1968). Carcinoma of the colon, ampulla of Vater and urinary bladder associated with familial multiple polyposis: a case report. Dis. Colon Rect., 11, 298-305.

Devic, A., and Bussy (1912). Un cas de polypose adénomateuse généralisée à tout l'intestin. Arch. Mal. Appar. dig., 6, 278-299.

Duncan, B. R., Dohner, V. A., and Priest, J. H. (1968). The Gardner syndrome: need for early diagnosis. J. Pediat., 72, 497-505.

Gardner, E. J., and Richards, R. C. (1953). Multiple cutaneous and subcutaneous lesions occurring simultaneously with hereditary polyposis and osteomatosis. Amer. J. hum. Genet., 5, 139-147.

Gorlin, R. J., and Chaudhry, A. P. (1960). Multiple osteomatosis, fibromas, lipomas, and fibrosarcomas of theskin and mesentery; epidermoid inclusion cysts of the skin, leicmyomas, and multiple intestinal polyposis. New Engl. J. Med., 263, 1151-1158.

Howard, J. W. (1943). Carcinoma of the duodenum. Amer. J. med. Sci., 206, 735-746.

ovine, V. M., and Tsangaris, N. (1961). Primary carcincma of the duodenum. Amer. Surg., 27, 744-750.

Jones, E. L., and Cornell, W. P. (1966). Gardner's syndrome. Arch. Surg., 92, 287-300.

MacDonald, J. M., Davis, W. C., Crago, H. R., and Berk, A. D. (1967). Gardner's syndrome and'periampullar malignancy. Amer. J. Surg., 113, 425-430.

Muir, E. G., Bell, A. J. Y., and Barlow, K. A. (1967). Multiple primary carcinomata of the colon, duodenum and larynx associated with kerato-acanthomata of the face. Brit. $J$. Surg., 54, 191-195.

Veale, A. M. O. (1960). Clinical and genetic problems in familial intestinal polyposis. Gut, 1, 285-290.

Weston, S. D., and Wiener, M. (1967). Familial polyposis associated with a new type of soft-tissue lesion (skin pigmentation): report of three cases and a review of the literature. Dis. Colon Rect., 10, 311-321. 